\title{
Dielectric and Ac Conductivity Studies of Mn-Doped $\mathrm{Na}_{1.86} \mathrm{Li}_{0.10} \mathrm{~K}_{0.04} \mathrm{Ti}_{3} \mathrm{O}_{7}$ Ceramics
}

\author{
R. Singh And ShripaL* \\ Department of Physics, P.P.N. College, Kanpur-208001, India \\ (Received December 14, 2012; in final form May 23, 2013)
}

\begin{abstract}
Dielectric-spectroscopic and ac conductivity studies on 0.01 and 1.0 molar percentage manganese doped layered $\mathrm{Na}_{1.86} \mathrm{Li}_{0.10} \mathrm{~K}_{0.04} \mathrm{Ti}_{3} \mathrm{O}_{7}$ ceramics have been reported. The dependence of loss tangent $(\tan \delta)$ and relative permittivity $\left(\varepsilon_{\mathrm{r}}\right)$ on temperature in the range $350-775 \mathrm{~K}$ and on frequency in the range $10 \mathrm{kHz}-1 \mathrm{MHz}$ have been undertaken. The losses are the characteristics of dipole mechanism, electrical conduction and space charge polarization. The obtained conductivity plots between $\log \left(\sigma_{\mathrm{ac}} T\right)$ versus $1000 / T$ have been divided into four regions namely region I, II, III, and IV. The mechanism of conduction in region I is acknowledged to electronic hopping conduction. The less frequency and more temperature dependent region II is ascribed as a mixed mechanism "associated interlayer ionic conduction, electron hopping, and alkali ion hopping conduction". The unassociated interlayer ionic conduction along with alkali ion hopping conduction mechanisms are contributing to the transport process in the mid temperature region III. The mechanism of conduction in the highest temperature region IV may be recognized as the modified interlayer ionic conduction. The conductivity versus frequency curves lead to conclude that the electronic hopping conduction diminishes with the rise of temperature.
\end{abstract}

DOI: 10.12693/APhysPolA.125.67

PACS 72.10.Bg, 72.20.Ee, 72.60.+g, 77.22.-d, 77.22.Gm, 77.22.Jp

\section{Introduction}

Alkali titanates $\left(\mathrm{Na}_{2} \mathrm{Ti}_{3} \mathrm{O}_{7}\right)$ exhibit unique nature of dielectrics and electrical properties, which makes them potentially useful for applications, such as solar energy conversion, electro chromic, self-cleaning devices, gas sensor, high-energy cell and environmental purification [1-4]. Studies uphold that layered titanates are usually composed of slipped or corrugated host layers of edge-shared $\mathrm{TiO}_{6}$ octahedra and interlayer alkali-metal cations $\left(\mathrm{Na}^{+}\right.$, $\mathrm{K}^{+}$, or $\mathrm{H}^{+} / \mathrm{H}_{3} \mathrm{O}^{+}$) in protonic form [5]. The corrugated sheets of $\mathrm{Na}_{2} \mathrm{Ti}_{3} \mathrm{O}_{7}$ or $\mathrm{K}_{2} \mathrm{Ti}_{4} \mathrm{O}_{9}$ are obtained by vertex sharing of such three or four multiple units, respectively, two of which have one unshared corner [6]. These typical titanate oxides possessing layered structure, in view to study its optical properties, ionic and electronic conductivities have been investigated due to their applications in the industry as ion exchangers, electrodes for secondary batteries, filters, reinforcements, heat insulators etc. [7-13]. Recently, visible light induced electron transfer and long-lived charge separation in cyanine dye/ layered titanate compounds have been studied [14].

The electrochemical and calorimetric thermo-dynamical properties of $\mathrm{Na}_{2} \mathrm{Ti}_{3} \mathrm{O}_{7}$ and $\mathrm{Na}_{2} \mathrm{Ti}_{6} \mathrm{O}_{13}$ have also been determined [15]. The available investigations [16] on preparation, kinetics and performance studies of mixed ionic and electronic conducting electrodes (MIEE) applied in alkali metal thermal to electric converter (AMTEC) found that $\mathrm{Ni}$ /sodium titanates electrodes with 4:1 mass ratio of metal/ceramic displayed

*corresponding author; e-mail: shripalsharmappn@gmail.com the best performance and longest life time among all tested electrodes. These investigations further concluded that the developing a MIEE is an attractive alternative to improve the efficiency of AMTEC. Moreover, structures which allow fast ion transports are generally disordered channeled or layered [16].

In a recent work iron, manganese and copper doped derivatives of $\mathrm{Na}_{2} \mathrm{Ti}_{3} \mathrm{O}_{7}, \mathrm{~K}_{2} \mathrm{Ti}_{4} \mathrm{O}_{9}, \quad \mathrm{Na}_{2-x} \mathrm{~K}_{x} \mathrm{Ti}_{3} \mathrm{O}_{7}$, $\mathrm{K}_{2-x} \mathrm{Na}_{x} \mathrm{Ti}_{3} \mathrm{O}_{7}$ fine ceramics have been characterized through X-ray diffraction (XRD), EPR, dc/ac conductivity, and dielectric-spectroscopic investigations [17-21]. Dielectric-spectroscopic and ac conductivity investigations on the layered $\mathrm{K}_{1.9} \mathrm{Rb}_{0.1} \mathrm{Ti}_{4} \mathrm{O}_{9}$ fine ceramics [22] and dc conductivity coupled with EPR investigations of manganese doped layered $\mathrm{Na}_{1.86} \mathrm{Li}_{0.10} \mathrm{~K}_{0.04} \mathrm{Ti}_{3} \mathrm{O}_{7}$ have been already published [23]. Very recently, we reported the effects of copper doping on dielectric and ac conductivity in layered sodium tri-titanate ceramic $[24]$ and dielectric behavior of layered $\mathrm{Na}_{2-x-y} \mathrm{Li}_{x} \mathrm{~K}_{y} \mathrm{Ti}_{3} \mathrm{O}_{7}$ ceramics [25]. Senguttuvan et al. reported lowest voltage ever reported oxide insertion electrode for sodium ion batteries [26]. Very recently, Redola et al. reported the electrochemical properties of $\mathrm{Na}_{2} \mathrm{Ti}_{3} \mathrm{O}_{7}$, a potential non-carbon based, low-voltage anode material for room temperature sodium ion battery applications [27].

In this manuscript, the investigations on dielectric-spectroscopic and ac conductivity studies of manganese doped $\mathrm{Na}_{1.86} \mathrm{Li}_{0.10} \mathrm{~K}_{0.04} \mathrm{Ti}_{3} \mathrm{O}_{7}$ ceramics are reported.

\section{Experimental}

Layered polycrystalline composition $\mathrm{Na}_{1.86} \mathrm{Li}_{0.10} \mathrm{~K}_{0.04} \mathrm{Ti}_{3} \mathrm{O}_{7}$ (denoted as SLPT-3) has been synthesized by mixing $\mathrm{Na}_{2} \mathrm{CO}_{3}, \mathrm{Li}_{2} \mathrm{CO}_{2}, \mathrm{~K}_{2} \mathrm{CO}_{2}$ 
and $\mathrm{TiO}_{2}$ (Merck Germany, A.R. grade) powders in appropriate molar ratio by sintering process. Manganese doped derivatives have been prepared by adding 0.01 and 1.0 molar percentage of $\mathrm{MnO}_{2}$ (Merck Germany, A.R. grade) powder in the base matrix of $\mathrm{Na}_{1.86} \mathrm{Li}_{0.10} \mathrm{~K}_{0.04} \mathrm{Ti}_{3} \mathrm{O}_{7}$ ceramic. The resulting mixture was grinded mechanically uniformly to yield a fine powder, heated at $1173 \mathrm{~K}$ for $12 \mathrm{~h}$ and then cooled at a rate of $3.0 \mathrm{~K} / \mathrm{min}$. The powder was mixed mechanically again and compressed at $10 \mathrm{MPa}$ to get pellets. These 0.01 and 1.0 mol.\% pelletized sintered compositions may be denoted as $\mathrm{M}_{1}$ SLPT- 3 and $\mathrm{M}_{2}$ SLPT- 3 , respectively. Details about the methods of preparation of pelletized doped compounds are similar to that reported earlier [17].

The X-ray diffraction patterns on mixed calcined powders of these manganese doped derivatives in a wide range of the Bragg angle were recorded at room temperature with model Iso-Debyfle 2002, Richseifert \& Co. (West Germany) that uses $\mathrm{Cu} K_{\alpha}$ radiation with the following settings: sweep $=3.0^{\circ} / \mathrm{min}$, range $(\mathrm{CPM})=5 \mathrm{k}$, time constant $=10.0$, target $=\mathrm{Cu}$, current $=20 \mathrm{~mA}$, voltage across the cathode and target $=20 \mathrm{kV}$.

For dielectric-spectroscopic and ac conductivity measurements a pelletized sample has been mounted in a sample holder and introduced in a cylindrical furnace. The chamber containing the sample holder is evacuated up to $10^{-3}$ mbar pressure. By using a precision digital LCR meter (Agilent $4284 \mathrm{~A}$ ) in the frequency scan from $10 \mathrm{kHz}$ to $1 \mathrm{MHz}$ at a temperature rate of $3 \mathrm{~K} / \mathrm{min}$ from $350 \mathrm{~K}<T<775 \mathrm{~K}$ with the help of a programmable temperature controller, the loss tangent $(\tan \delta)$, parallel capacitance $\left(C_{\mathrm{p}}\right)$ and relative permittivity $\left(\varepsilon_{\mathrm{r}}\right)$ have been measured directly at the desired values. From the measured data, ac conductivity has been evaluated using the following relation:

$$
\sigma_{\mathrm{ac}}=\left(\frac{t}{A}\right) \omega C_{\mathrm{P}} \tan \delta,
$$

where $t$ is the thickness, $A$ is the area of the cross-section of the pellet and $\omega$ is the frequency of measurement.

\section{Results and discussion}

XRD patterns indexed with reflection peaks obtained for $\mathrm{M}_{1}$ SLPT-3 and $\mathrm{M}_{2}$ SLPT-3 samples at room temperature (RT) are shown in Fig. 1. These reflection peaks coincide to that reported in the literature for $\mathrm{Na}_{2} \mathrm{Ti}_{3} \mathrm{O}_{7}$ and lithium potassium mixed $\mathrm{Na}_{2} \mathrm{Ti}_{3} \mathrm{O}_{7}[10,25]$ and does not contain any line characteristics of constituent oxides and carbonates. Thus, these XRD patterns confirm the formation of these polycrystalline alkali-metal titanates with a monoclinic crystal system, possessing a unit cell configuration based on good agreement of observed and reported values.

Figure $2 \mathrm{a}$ and $\mathrm{b}$ shows the loss tangent $(\tan \delta)$ versus temperature curves in the temperature range of 350 $775 \mathrm{~K}$ at some fixed frequencies for $\mathrm{M}_{1}$ SLPT-3 and $\mathrm{M}_{2}$ SLPT-3 samples, respectively. From these plots, it

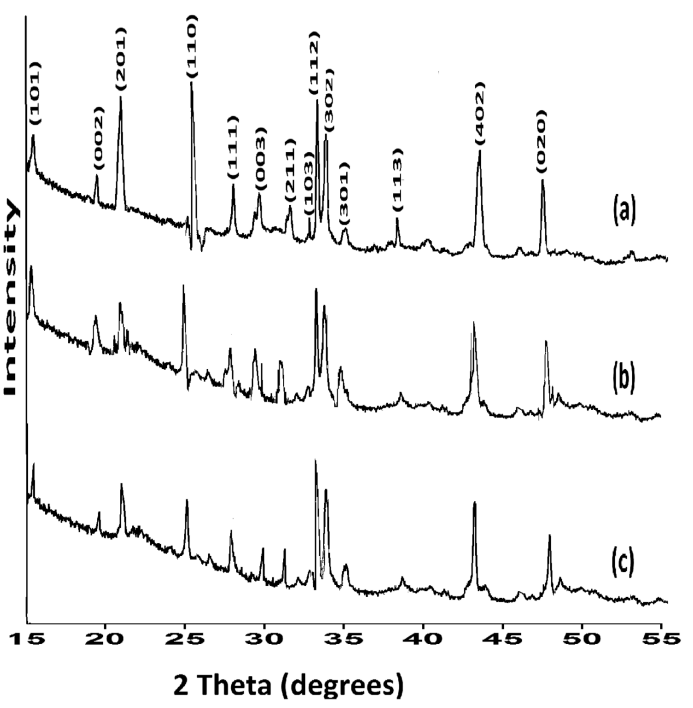

Fig. 1. XRD patterns recorded at room temperature for (a) SLPT-3, (b) $\mathrm{M}_{1}$ SLPT-3 and (c) $\mathrm{M}_{2}$ SLPT-3.

can be seen that the values of $\tan \delta$ remain invariant up to $500 \mathrm{~K}$ with the rise in temperature for both $\left(\mathrm{M}_{1} \mathrm{SLPT}-3\right.$ and $\mathrm{M}_{2} \mathrm{SLPT}-3$ ) compositions. Above $500 \mathrm{~K}$, the values of $\tan \delta$ increase with the rise in temperature giving a broad peak at $750 \mathrm{~K}$ for $\mathrm{M}_{1} \mathrm{SLPT}-3$ and small peak at $650 \mathrm{~K}$ for $\mathrm{M}_{2} \mathrm{SLPT}-3$ layered ceramics. At higher temperature, it can be seen that the rate of increase of $\tan \delta$ is higher at lower frequencies. This may be due to space charge polarization [28]. The general increase in $\tan \delta$ with temperature may be explained by knowing the fact that the number of ions that take part in polarization continuously grow with the rise in temperature [29]. The thermal energy may also aid in overcoming the activation barrier for the orientation of polar molecules in the direction of the field.

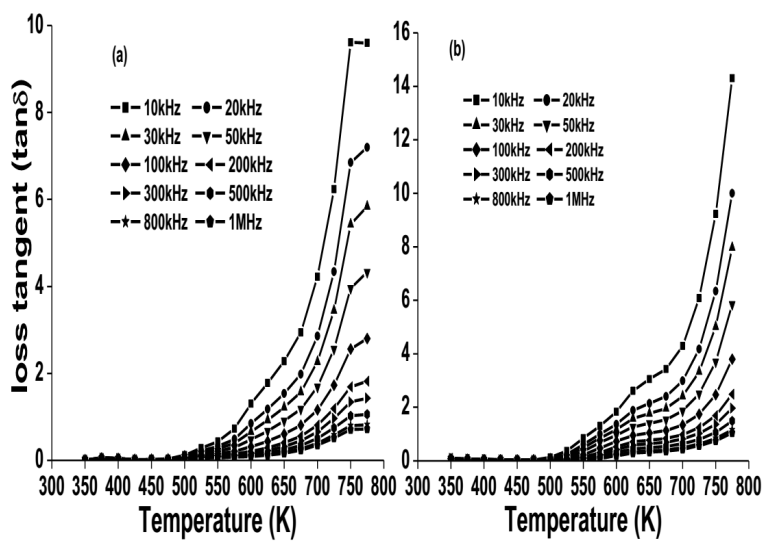

Fig. 2. Loss tangent $(\tan \delta)$ versus temperature plots at different frequencies for (a) $\mathrm{M}_{1}$ SLPT-3 and (b) $\mathrm{M}_{2}$ SLPT-3.

Here, the ionic variations associated with dielectric losses depend up on two facts: (i) the dielectric losses 
which depend on temperature and grow directly with frequency are governed by polarization, (ii) the losses that rise with temperature in accordance with an exponential law but dependence on frequency are due to the motion of loosely bound ions. Here, the polarization process occurs as a function of temperature. The existence of the relaxation peak in $\tan \delta(T)$ curves may be due to the presence of different types of dipoles generated in the interlayer space after two types of manganese substitutions. At higher frequencies, ceramic materials offer low reactance to the sinusoidal signal to minimize the conduction losses and hence, the amount of dielectric loss decreases at higher frequencies. Thus, the mechanisms of losses existing in both $\mathrm{M}_{1}$ SLPT-3 and $\mathrm{M}_{2}$ SLPT-3 samples are of mixed character, i.e. dipole mechanism and electrical conduction $[29,30]$.

Figure $3 \mathrm{a}$ and $\mathrm{b}$ shows the variation of $\tan \delta$ with respect to frequency in the temperature range 350-775 K for $\mathrm{M}_{1} \mathrm{SLPT}-3$ and $\mathrm{M}_{2} \mathrm{SLPT}-3$ compositions, respectively. The results show that $\tan \delta$ decreases gradually in the lower temperature region but it decreases exponentially with rise in frequency towards higher temperature span. These trends are consistent for both the samples and reflect the feature of dielectric losses due to dipole orientation and electrical conduction. Furthermore, the observed noticeable decrease in $\tan \delta$ with the rise in frequency at high temperature is acknowledged to the presence of space charge polarization and is the outcome of low reactance offered by the ceramics materials [31].

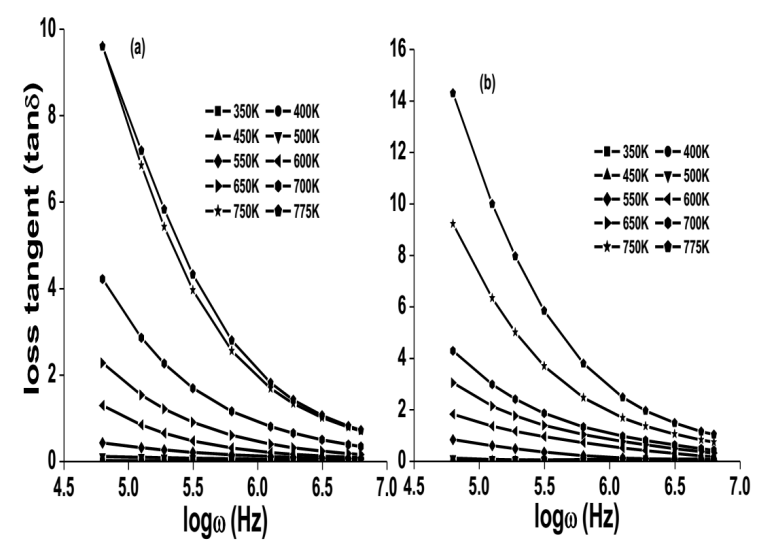

Fig. 3. Loss tangent $(\tan \delta)$ versus frequency plots at different temperatures for (a) $\mathrm{M}_{1} \mathrm{SLPT}-3$ and (b) $\mathrm{M}_{2}$ SLPT-3.

Figure 4 shows the dependence of $\tan \delta$ as a function of frequency at $775 \mathrm{~K}$ for both the samples. It can be seen from the plot that the trend of variations is very similar for $\mathrm{M}_{1}$ SLPT- 3 and $\mathrm{M}_{2}$ SLPT-3 samples but the numerical values of $\tan \delta$ for $\mathrm{M}_{1} \mathrm{SLPT}-3$ are less than that for $\mathrm{M}_{2} \mathrm{SLPT}-3$ suggesting that the $\mathrm{Mn}^{2+}$ ions substitute at $\mathrm{Na}_{(2)}$ site. Moreover, the large number of $\mathrm{Mn}^{2+}$ ions substitution at $\mathrm{Na}_{(1)}$ site increases the interlayer space. However, the numerical values of $\tan \delta$ for both these compositions are much higher than that of undoped $\mathrm{Na}_{1.86} \mathrm{Li}_{0.10} \mathrm{~K}_{0.04} \mathrm{Ti}_{3} \mathrm{O}_{7}$ (SLPT-3) as well as $\mathrm{Na}_{1.89} \mathrm{Li}_{0.10} \mathrm{~K}_{0.01} \mathrm{Ti}_{3} \mathrm{O}_{7}$ (SLPT-1) and $\mathrm{Na}_{1.88} \mathrm{Li}_{0.10} \mathrm{~K}_{0.02} \mathrm{Ti}_{3} \mathrm{O}_{7}$ (SLPT-2) samples [25]. This difference may be due to the formation of a special type of linkage among $\mathrm{Na}_{1.86} \mathrm{Li}_{0.10} \mathrm{~K}_{0.04} \mathrm{Ti}_{3} \mathrm{O}_{7}(\mathrm{Mn}-\mathrm{Na} / \mathrm{Li} / \mathrm{K} /$ $-\mathrm{Ti}-\mathrm{O})$ lattice to spare some of the cloud like electrons responsible for giving such a trend of dielectric losses due to the manganese substitution at both interlayer $\mathrm{Na}_{(1)}$ and $\mathrm{Na}_{(2)}$ sites. Thus, it can be concluded that the losses are of mixed character, i.e. dipolar losses, space charge polarizations and the losses due to electric conduction.

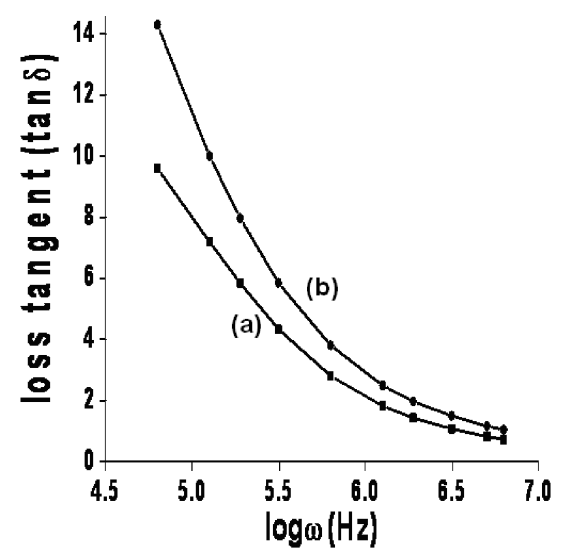

Fig. 4. Loss tangent $(\tan \delta)$ versus frequency plots at $775 \mathrm{~K}$ for (a) $\mathrm{M}_{1}$ SLPT-3 and (b) $\mathrm{M}_{2}$ SLPT-3.

Figure 5a and $\mathrm{b}$ shows the dependence of relative permittivity $\left(\varepsilon_{\mathrm{r}}\right)$ on temperature at some fixed frequencies for $\mathrm{M}_{1} \mathrm{SLPT}-3$ and $\mathrm{M}_{2} \mathrm{SLPT}-3$ samples, respectively. It can be seen that $\varepsilon_{\mathrm{r}}$ remains almost invariant with the rise in temperature up to $475 \mathrm{~K}$ for $\mathrm{M}_{1} \mathrm{SLPT}-3$ and $525 \mathrm{~K}$ for $\mathrm{M}_{2} \mathrm{SLPT}-3$ sample. Towards higher temperature, the value of $\varepsilon_{\mathrm{r}}$ increases slowly furnishing two peaks at $550 \mathrm{~K}$ and $750 \mathrm{~K}$ for $\mathrm{M}_{1}$ SLPT-3 and one peak at $625 \mathrm{~K}$ for $\mathrm{M}_{2} \mathrm{SLPT}-3$, then increases with further rise in temperature. All these $\varepsilon_{\mathrm{r}}(T)$ plots indicate that the values of $\varepsilon_{\mathrm{r}}$ are invariant with the rise in frequency at lower temperatures. However, values of $\varepsilon_{\mathrm{r}}$ are unaffected by manganese substitution in the $\mathrm{Na}_{1.86} \mathrm{Li}_{0.10} \mathrm{~K}_{0.04} \mathrm{Ti}_{3} \mathrm{O}_{7}$ lattice at lower temperatures, while at elevated temperatures, the values of $\varepsilon_{\mathrm{r}}$ increases significantly for both the compositions. This may be attributed to the growth in the number of dipoles due to substitution of manganese as $\mathrm{Mn}^{3+}$ at $\mathrm{Ti}^{4+}$ sites and as $\mathrm{Mn}^{2+}$ at interlayer alkali $\left(\mathrm{Na}_{(1)} / \mathrm{Na}_{(2)}\right)$ sites in these materials. However, the average values of $\varepsilon_{\mathrm{r}}$ for $\mathrm{M}_{1}$ SLPT- 3 and $\mathrm{M}_{2} \mathrm{SLPT}-3$ samples are much higher than that of all SLPT samples and other manganese doped derivatives of SLPT-1 and SLPT-2 [32].

Figure $6 \mathrm{a}$ and $\mathrm{b}$ shows relative permittivity $\left(\varepsilon_{\mathrm{r}}\right)$ versus frequency curves for $\mathrm{M}_{1} \mathrm{SLPT}-3$ and $\mathrm{M}_{2}$ SLPT -3 at various temperatures. From the plots, it is clear that there is a very little variation in $\varepsilon_{\mathrm{r}}$ with frequency at lower (below $550 \mathrm{~K}$ ) temperatures. At higher temperatures (above $550 \mathrm{~K}), \varepsilon_{\mathrm{r}}$ decreases exponentially with rise in temper- 


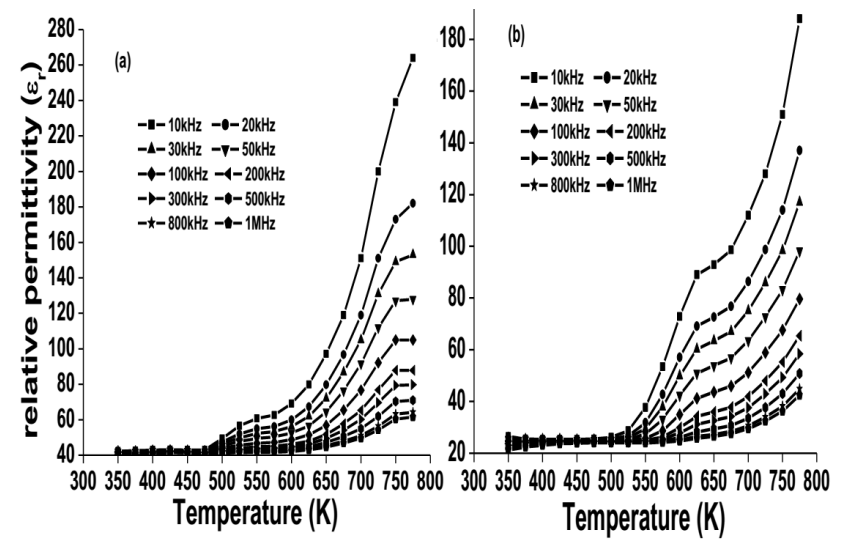

Fig. 5. Relative permittivity $\left(\varepsilon_{r}\right)$ versus temperature plots at different frequencies for (a) $\mathrm{M}_{1}$ SLPT-3 and (b) $\mathrm{M}_{2}$ SLPT-3.

ature exhibiting polar nature of the materials. Such a nature of curves indicates the significant contribution of polarization properties in these materials. However, in these curves, the higher values of $\varepsilon_{\mathrm{r}}$ at lower frequencies of the applied electric field may be understood due to the occurrence of space charge polarization.
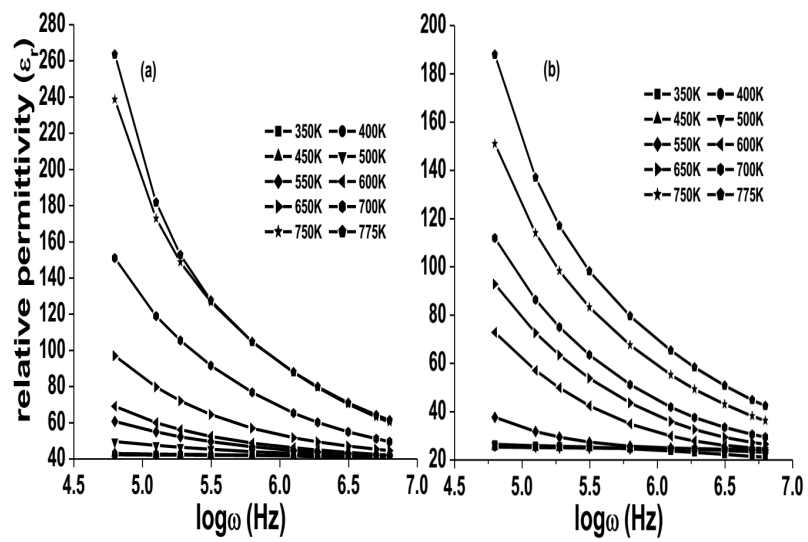

Fig. 6. Relative permittivity $\left(\varepsilon_{\mathrm{r}}\right)$ versus frequency plots at different temperatures for (a) $\mathrm{M}_{1} \mathrm{SLPT}-3$ and (b) $\mathrm{M}_{2}$ SLPT-3.

The variation of $\varepsilon_{\mathrm{r}}$ as the function of frequency at $775 \mathrm{~K}$ for $\mathrm{M}_{1}$ SLPT-3 and $\mathrm{M}_{2}$ SLPT-3 is shown in Fig. 7. In the entire frequency range of investigation, the values of $\varepsilon_{\mathrm{r}}$ are greater for $\mathrm{M}_{1}$ SLPT- 3 than that for $\mathrm{M}_{2}$ SLPT-3. This can be understood by the knowledge of manganese substitutions as $\mathrm{Mn}^{3+}$ at $\mathrm{Ti}^{4+}$ sites of $\mathrm{M}_{1}$ SLPT-3 derivative and as $\mathrm{Mn}^{2+}$ at two different $\mathrm{Na}_{(1)}$ and $\mathrm{Na}_{(2)}$ sites in the interlayer space of $\mathrm{M}_{2} \mathrm{SLPT}-3$ discussed as above.

Figure $8 \mathrm{a}$ and b shows $\log (\sigma T)$ versus $1000 / T$ plots for $\mathrm{M}_{1}$ SLPT-3 and $\mathrm{M}_{2}$ SLPT-3 samples at various fixed frequencies. These materials are prepared by solid state sintering process which gives rise to the microscopic chemical heterogeneities in the local regions. Different micro-

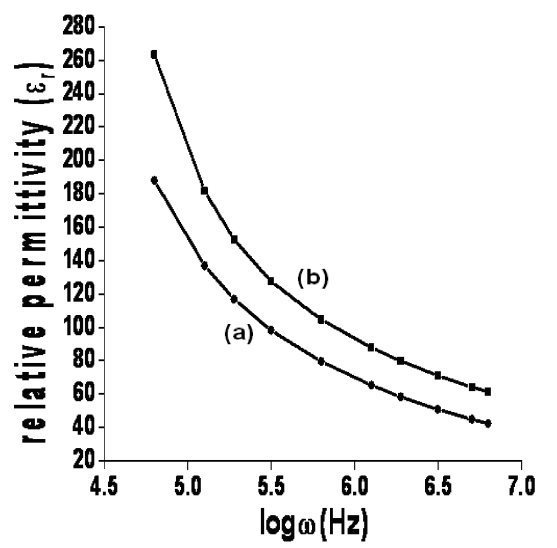

Fig. 7. Relative permittivity $\left(\varepsilon_{\mathrm{r}}\right)$ versus frequency plots at $775 \mathrm{~K}$ for (a) $\mathrm{M}_{1}$ SLPT-3 and (b) $\mathrm{M}_{2}$ SLPT-3.

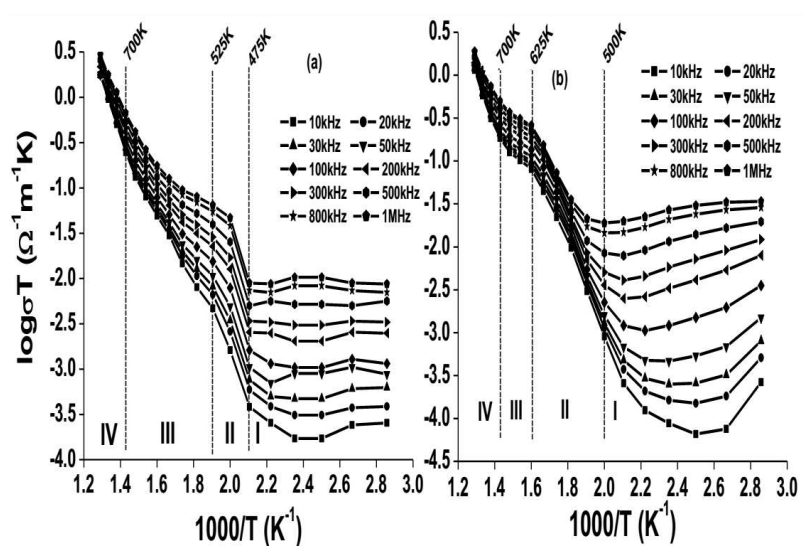

Fig. 8. $\log (\sigma T)$ versus $1000 / T$ plots at different frequencies for (a) $M_{1}$ SLPT-3 and (b) M $M_{2}$ SLPT-3.

scopic regions have different conductivities because different compositions give rise to interfacial polarization. The obtained conductivity curves are divided into four distinct regions as discussed below.

\subsection{Region $I$}

This region extends up to $475 \mathrm{~K}$ and $500 \mathrm{~K}$ for the samples $\mathrm{M}_{1}$ SLPT-3 and $\mathrm{M}_{2} \mathrm{SLPT}-3$, respectively. From these curves, strong frequency with little temperature dependence of ac conductivity is observed in both samples. It is clear from the curves that the electronic hopping conduction is leading towards lower temperature and diminishes with the rise in temperature. A number of workers [33-35] interpreted it by proposing the ac conductivity due to the hopping conduction with the increase of frequency $(\omega)$. However, observed ac conductivity values for $\mathrm{M}_{1}$ SLPT-3 sample are almost similar with SLPT-3 but the values for $\mathrm{M}_{2} \mathrm{SLPT}-3$ are greater than undoped SLPT-3 sample [32]. Electronic hopping conduction has already been proposed to occur for pure and manganese doped samples through loose electrons from $\left(\mathrm{Ti}_{3} \mathrm{O}_{7}\right)^{2-}$ groups jumping from one $\mathrm{Ti}-\mathrm{Ti}$ chain to 
the adjacent one [21] and these investigations support it. Thus, electronic hopping conduction could take place for such samples.

\subsection{Region II}

This nature does not exist for $\mathrm{M}_{2} \mathrm{SLPT}-3$ in which a large number of manganese ions situated at $\mathrm{Na}(1) / \mathrm{Na}_{(2)}$ interlayer sites make a compensatory configuration arising against that configuration which was responsible for giving a relaxation type peak appearing at $500 \mathrm{~K}$ for $\mathrm{M}_{1}$ SLPT-3 M1SLPT-3 at higher frequencies (above 100 $\mathrm{kHz}$ ). In this region, the variation of ac conductivity is less frequency and more temperature dependent. The slope of conductivity plots is higher than that of region I, so the mechanism of conduction may be attributed due to associated interlayer ionic conduction as proposed earlier [17]. The relaxation type peak appears at $500 \mathrm{~K}$ for $\mathrm{M}_{1}$ SLPT-3 at higher frequencies (above $100 \mathrm{kHz}$ ) that are not resolved for higher frequencies. The appearance of this peak for $\mathrm{M}_{1} \mathrm{SLPT}-3$ may be due to the two happenings: (i) presence of some more $\mathrm{K}^{+}$ions in the interlayer space than in SLPT-1 and SLPT-2 and (ii) manganese substitutions at $\mathrm{Ti}^{4+}$ sites. Accordingly, $\mathrm{Na}-\mathrm{Li}$ / $\mathrm{K}-\mathrm{Ti} / \mathrm{Mn}$ configuration results in such a relaxation type peak. This nature does not exist for $\mathrm{M}_{2}$ SLPT-3 due to high doping concentration in which a large number of manganese ions situated at $\left(\mathrm{Na}_{(1)} / \mathrm{Na}_{(2)}\right)$ alkali interlayer sites make a compensatory configuration arising against that configuration which was responsible for giving a relaxation type peak appearing at $500 \mathrm{~K}$ for $\mathrm{M}_{1}$ SLPT-3 at higher frequencies (above $100 \mathrm{kHz}$ ) and reduce the effect of frequency.

Furthermore, with the increase of doping and after saturating the $\mathrm{Ti}^{4+}$ sites, some alkali $\left(\mathrm{Na}_{(1)} / \mathrm{Na}_{(2)}\right)$ ions are replaced by manganese as $\mathrm{Mn}^{2+}$ ions in the interlayer space of $\mathrm{M}_{1}$ SLPT- 3 and $\mathrm{M}_{2}$ SLPT- 3 lattices. The change in the interlayer space with the increase in the impurity content would cause a corresponding change in the values of conductivity and respective slopes.

Accordingly, conduction in this region may easily be understood as a mixed mechanism "associated interlayer ionic conduction, electron hopping and alkali ion hopping conduction".

\subsection{Region III}

This region exists in the temperature range $525-700 \mathrm{~K}$ for $\mathrm{M}_{1} \mathrm{SLPT}-3$ and $625-700 \mathrm{~K}$ for $\mathrm{M}_{2} \mathrm{SLPT}-3$. It can be seen from Fig. $8 \mathrm{a}$ and $\mathrm{b}$ that conductivity is less frequency and strong temperature dependent for $\mathrm{M}_{1} \mathrm{SLPT}-3$, but frequency dependent and less temperature dependent for $\mathrm{M}_{2}$ SLPT-3 in this region.

As we know that $I-V$ pairs formed in region II are probably break up to the lower limit of this region and have been already explained [21]. In this region, the results show that the slope of conductivity plots for $\mathrm{M}_{1}$ SLPT-3 is higher than that of SLPT-3 and $\mathrm{M}_{2}$ SLPT-3, which indicates the existence of unassociated interlayer ionic conduction along with alkali ion hopping conduction.

So, the conduction mechanism in this region can be understood as unassociated interlayer ionic conduction along with the alkali ion hopping conduction.

\subsection{Region IV}

This highest temperature region exists above $700 \mathrm{~K}$ for both $\mathrm{M}_{1}$ SLPT- 3 and $\mathrm{M}_{2}$ SLPT-3 samples. For both samples, the ac conductivity seems to be least frequency and highly temperature dependent. The nature of the plots for both compositions is similar and slope is higher than that found in previous regions. Accordingly, the conduction in this region is modified interlayer ionic conduction as discussed earlier [36] along with alkali ion hopping conduction. Therefore, the conduction mechanism in this region is modified interlayer ionic conduction along with the alkali ion hopping conduction.

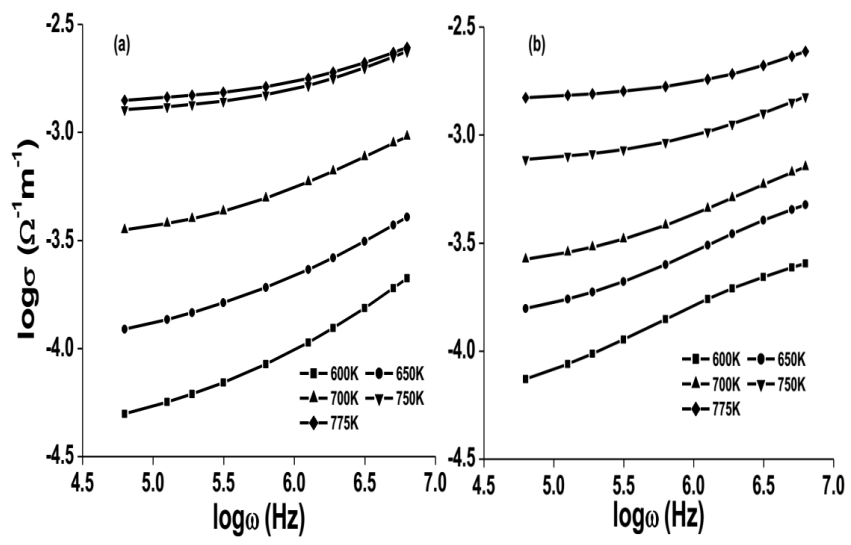

Fig. 9. $\log (\sigma)$ versus frequency plots at different temperatures for (a) $\mathrm{M}_{1}$ SLPT-3 and (b) $\mathrm{M}_{2}$ SLPT-3.

The conductivity $\log (\sigma)$ versus frequency $\log (\omega)$ variations are given in Fig. 9a and b. From these plots, it can be seen that ac conductivity shows almost a linear variation with frequency at some fixed temperatures. For these samples, slopes are decreasing with the rise in temperature. As we know, every material has some free charges and under the applied low frequency, these charges can follow the field and cause conduction currents [37]. Polycrystalline materials have a short range order up to few molecular distances. Many research groups [33-35] have interpreted such a behavior of conductivity due to the electronic hopping conduction and the ac conductivity shows almost a linear variation with frequency. Towards higher temperatures, we propose that alkali ion hopping conduction mechanism is responsible for frequency dependence of conductivity.

\section{Conclusions}

The present study leads to the following conclusions:

(i) Dielectric-spectroscopic investigations show the presence of dipole mechanism of losses along with the 
losses due to the motion of loosely bound ions and space charge polarization at higher temperature. Thus, these manganese doped derivatives demonstrate the polar nature of the compounds. (ii) Two types of manganese substitutions in the interlayer space have been acknowledged through $\tan \delta / \varepsilon_{\mathrm{r}}$ and $\log (\sigma T)$ versus temperature plots for both the doped derivatives. (iii) The electronic hopping conduction is dominant in the lower temperature region I which diminishes with the rise in temperature. (iv) A variety of conduction mechanisms like associated interlayer ionic conduction with electron and alkali ion hopping conduction, unassociated interlayer ionic conduction with alkali ion hopping conduction and then modified interlayer ionic conduction along with the alkali ion hopping conduction leading in regions II, III, and IV, respectively. (v) Manganese doped derivatives of layered lithium and potassium mixed sodium tri-titanates ceramic can be mixed ionic-electronic materials.

\section{Acknowledgments}

The author (R. Singh) would like to thank University Grants Commission (UGC) of India for his Ph.D. financial support through RGNF [No. F. 14-2(SC)/ 2008 (SA-III)]. We also thank Prof. K.K. Raina, School of Physics and Materials Science, Thapar University, Patiala-147004, India for providing the experimental facilities of dielectric-spectroscopic and ac conductivity measurements. The suggestions of reviewer's were certainly found useful while modifying the paper.

\section{References}

[1] L. Viciu, V. Golub, J. Wiley, J. Solid State Chem. 175, 88 (2003).

[2] R. Seshadri, C. Martin, M. Herin, B. Raveau, C. Rao, Chem. Mater. 9, 270 (1997).

[3] A. Fujishima, K. Honda, Nature 238, 37 (1972).

[4] G. Dagon, M. Tomkiewicz, J. Phys. Chem. 97, 12651 (1993).

[5] A. Verbaere, M. Tournoux, Bull. Soc. Chim. France 4, 1237 (1973).

[6] M. Dion, Y. Piffard, M. Tournoux, J. Inorg. Nucl. Chem. 40, 917 (1978).

[7] A. Kudo, T. Sakata, J. Mater. Chem. 3, 1081 (1993).

[8] A. Kudo, T. Kondo, J. Mater. Chem. 7, 777 (1997).

[9] M. Shabita, A. Kudo, A. Tanaka, K. Maruya, T. Onishi, Chem. Lett. 6, 1017 (1987).

[10] S. Anderson, A.D. Wadsley, Acta Chem. Scand. 15, 663 (1961).

[11] M. Koizumi, S. Yoshikawa, H. Izawa, Japan Patent Kukai Tokkyo Koho JP 62, 100411 (1987).

[12] T. Sasaki, M. Watanabe, Y. Konatsu, Y. Fujiki, Inorg. Chem. 24, 2265 (1985).

[13] M. Sugita, M. Tsuji, M. Abe, Bull. Chem. Soc. Jpn. 63, 1978 (1990).
[14] N. Miyamoto, K. Kuroda, M. Ogawa, J. Phys. Chem. B 108, 4268 (2004).

[15] M. Holzinger, A. Benisek, W. Schnellelle, E. Gmelin, J. Maier, W. Sitte, J. Chem. Thermodyn. 35, 1469 (2003).

[16] G. Yuyan, Ph.D. Thesis, Texas A \& M University, USA 2006

[17] Shripal, D. Maurya, Shalini, J. Kumar, Mater. Sci. Eng. B 136, 5 (2007).

[18] Shripal, S. Badhwar, D. Maurya, J. Kumar, R.P. Tandon, in: Advances in Condens. Matter Physics, Ed. K.K. Raina, Allied Publisher, New Delhi 2005, p. 250.

[19] Shripal, S. Badhwar, Shalini, R.P. Tandon, in: $A d-$ vances in Technologically Important Crystals, Eds. B. Kumar, R.P. Tandon, Macmillan India Ltd., New Delhi 2006, p. 628 .

[20] S. Badhwar, D. Maurya, R. Bilas, Shripal, in: Proc. DAE Solid State Physics Symp., Eds. V.K. Aswal, H.G. Salunke, J.V. Yakhmi, Prime Time Education, Mumbai 2005, p. 709.

[21] D. Maurya, J. Kumar, Shripal, J. Phys. Chem. Solids 66, 1614 (2005).

[22] Shripal, L.N. Pandey, D.C. Dwivedi, R. Singh, R.P. Tandon, Integrat. Ferroelectr. 120, 28 (2010).

[23] Shripal, Geetika, R. Singh, R.P. Tandon, Integrat. Ferroelectr. 120, 18 (2010).

[24] Shripal, S. Dwivedi, R. Singh, R.P. Tandon, Int. J. Mod. Phys. B 27, 1350144-1(2013).

[25] Shripal, R. Singh, Geetika, R.K. Shukla, K.K. Raina, J. Adv. Dielectr. 4, 429 (2011).

[26] P. Senguttuvan, G. Rousse, V. Seznec, J.M. Tarascon, M.R. Palacín, Chem. Mater. 23, 4109 (2011).

[27] A. Rudola, K. Saravanan, C.W. Mason, P. Balaya, J. Mater. Chem. A 1, 2653 (2013).

[28] B.P. Das, R.N.P. Chaudhary, P.K. Mahapatra, Mater. Sci. Eng. B 104, 96 (2003).

[29] N.P. Bogoroditsky, V.V. Pasynkov, B. Tareev, Electrical Engineering Materials, Mir Pub., Moscow 1979.

[30] B. Tareev, Physics of Dielectric Materials, Mir Pub., Moscow 1979

[31] V. Langwal, B.S. Semwal, N.S. Panwar, Bull. Mater. Sci. 26, 619 (2003).

[32] R. Singh, Ph.D. Thesis, C.S.J.M. University, India 2012.

[33] G. Austin, N.F. Mott, Adv. Phys. 18, 41 (1969).

[34] M. Pollack, Philos. Mag. 23, 519 (1971).

[35] M. Bottger, V.V. Breyksin, Phys. Status Solidi 9, 79 (1976).

[36] S.D. Pandey, R.K. Sharma, Shripal, in: Proc. Fifth Asia Pacific Conf., Eds. S.P. Chia, K.S. Low, M. Othman, C.S. Wong, A.C. Chew, S.P. Moo, World Sci., Singapore 1992, p. 866.

[37] J.C. Dyre, B.S. Thomas, Rev. Mod. Phys. 72, 873 (2000). 